\title{
PHẪU THUẬT ĐÎ̀̂U TRỊ ĐộNG KINH THÙY THÁI DƯƠNG
}

\author{
Lê Viết Thắng*, Lê Thụy Minh An*, Nguyễn Phạm Bảo Quốc*, \\ Lê Văn Tuấn*, Nguyễn Huệ Đức*; Phạm Anh Tuấn*, Nguyễn Minh Anh*
}

\section{TÓM TĂT}

Mục tiêu. Đánh giá vai trò và kết quả phẫu thuật điều trị động kinh thùy thái dương. Phương pháp. Tất cả bệnh nhân được chẩn đoán xác định động kinh thùy thái dương phù hợp cộng hưởng từ sọ não và điện não đồ (thoả tiêu chuẩn lâm sàng - hình ảnh học - điện sinh lý). Nghiên cứu can thiệp trên một nhóm dân số, so sánh trước và sau điều tri, từ 01/2016 12/2020 tại khoa Ngoại Thần Kinh, bệnh viện Đại hoc Y Dược thành phố Hồ Chí Minh và bệnh viện Nguyển Tri Phương. Kết quả: Trong 56 bệnh nhân, tỉ lệ là 26 nam: 30 nữ, tuổi trung bình 39,2. Tất cả trường hợp có cơn động kinh cục bộ (100\%), cơn cục bộ đơn giản $(30,4 \%)$, cơn cục bô phức tap $(69,6 \%)$. Vi trí tổn thương ở vỏ não thái dương $(71,4 \%)$ và thái dương trong $(28,6 \%)$. Thời gian theo dõi trung bình 12 tháng (6-48 tháng), 87,5\% bệnh nhân hết cơn động kinh sau phẫu thuật. Thuốc chống động kinh giảm trong $100 \%$ trường hợp so với trước phẫu thuật. Kết luận: Chứng tôi ghi nhận tỉ lệ cao hết cơn động kinh sau phẫu thuật động kinh thùy thái dướng có sang thương, thành công trong việc giảm thuốc chống động kinh. Chúng tôi tin tưởng rắng phẫu thuật là phướng pháp điều trị hiệu quả cao, biến chứng thấp trong động kinh thùy thái dương có sang thương.

Tư khóa: động kinh thùy thái dương có sang thương, hết cơn động kinh

\section{SUMMARY \\ SURGERY FOR LESIONAL TEMPORAL LOBE EPILEPSY TREAMENT}

Objective of the study: We investigated the utility of epilepsy surgery and postoperative outcome in patients with lesional temporal lobe epilepsy. Subjects and research methods: Patients were diagnosed temporal lobe epilepsy, presurgical evaluation tool based on semiology, electroencephalography and brain MRI with epilepsy protocol. This before and after study was conducted during $01 / 2016$ - $12 / 2020$ at Department of Neurosurgery in Ho Chi Minh City University Medical Center and Nguyen Tri Phuong hospital. Patients with a diagnosis of intractable lesional temporal lobe epilepsy and relevant focal abnormalities on EEG underwent epilepsy surgery and followed up $\geq 6$ months were included and evaluated for postoperative outcome. Results: A total of 56 patients, with a mean age of 39.2 years (20 male: 36 female), were studied. All of participants presented partial seizures, including

*Bệnh viện Đại Học Y Dược TP. Hồ Chí Minh Chịu trách nhiệm chính: Lê Viết Thắng Email: Drlevietthang@ump.edu.vn Ngày nhận bài: 17.11.2020

Ngày phản biện khoa học: 6.01.2021

Ngày duyệt bài: 19.01.2021 simple partial seizure $(30,4 \%)$, complex partial seizure (69.6\%). Temporal neocortex lesions (71.4\%) and mesial temporal lesions $(28.6 \%)$ were the most frequent etiologies. With a mean follow-up of 12 months (6-48 months), $87.5 \%$ of patients became seizure-free postoperatively. Anticonvulsants were reduced in $100 \%$ of the cases. Conclusions: We found high rates of seizure freedom after surgery in lesional epilepsy patients despite of limited facilities and infrastructure. Considering the favorable outcome of epilepsy surgery in our series, we believe that it is a major treatment option, even in less resourceintensive settings, and should be encouraged.

Keywords: Lesional temporal lobe epilepsy, seizure-free.

\section{I. ĐẶT VẤN ĐỀ}

Tỉ lệ lưu hành động kinh chiếm $1 \%$ dân số, trong đó $30 \%$ bệnh nhân kháng thuốc. Khoảng $1 / 2$ trường hợp kháng thuốc có sang thương não là ứng viên tiêm năng cho phẫu thuật động kinh [4], [5]. Phẫu thuật động kinh, đặc biệt là phẫu thuật thùy thái dương thường mang lại kết quả tốt sau phẫu thuật. Sang thương não trong bệnh nhân động kinh thùy thái dương không phải luôn là vùng sinh động kinh. Tổn thương vỏ não thái dương có thể là vùng sinh động kinh thứ phát từ hồi thái dương trong. Tần suất sang thương vỏ não thái dương kết hợp với xơ hóa hải mã chiếm 8-22\% [4]. Vì vậy, phẫu thuật lấy sang thương kết hợp với nhu mô xung quanh sang thương có thể mang lại kết quả tốt sau mổ. Việc đánh giá chính xác trước phấu thuật triệu chứng cơn động kinh, sang thương não trên cộng hưởng từ và hoạt động sóng bất thường trên điện não đồ, có sự đồng thuận cao có thể mang lại kết quả không cơn động kinh sau phẫu thuật [1].

\section{II. ĐỐI TƯỢNG VÀ PHƯƠNG PHÁP NGHIÊN CỨU}

Tất cả bệnh nhân được chẩn đoán xác định động kinh thùy thái dương phù hợp cộng hưởng từ sọ não và điện não đồ (thoả tiêu chuẩn lâm sàng - hình ảnh học - điện sinh lý) tại bệnh viện Đại học Y Dược thành phố Hồ Chí Minh và bệnh viện Nguyễn Tri Phương từ 01/01/2016 đến 31/12/2020.

Tiêu chuẩn chọn bệnh: Lâm sàng có động kinh thùy thái dương, tổn thương não liên quan đến động kinh, có khả năng chữa khỏi bằng phẫu thuật (surgically remediable epilepsy syndromes) trên cộng hưởng từ, phù hợp sóng chậm và gai động kinh trên điện não đồ bề mặt 
ngoài cơn và/hay trong cơn phù hợp với vị trí sang thương trên MRI.

Tiêu chuẩn loại trừ

- Bệnh vê tâm thân kinh nặng: trâm cảm, tâm thân phân liệt, rối loạn lưỡng cực, ...

- Nhiêu vùng sinh động kinh rải rác hai bán câu

- Bệnh thần kinh tiến triển: tai biến mạch máu nã̉o, viêm não,...

Nghiên cứu can thiệp trên một nhóm dân số được thiết kế so sánh trước và sau điêuu trị. Số liệu thu thập tại khoa Ngoại Thân Kinh bệnh viện ĐHYD TPHCM và bệnh viện Nguyễn Tri Phương từ 01/01/2016 đến 31/12/2020. Số liệu được thống kê bằng phần mềm SPSS 20.0.

Đánh giá trước phẫu thuật. Sau khi đánh giá trước phẫu thuật, có sự đồng thuận giữa triệu chứng cơn động kinh, sang thương não và sóng động kinh trên điện não đồ. Sang thương thùy thái dương được phân loại trên cộng hưởng từ theo vị trí hồi thái dương trong và vỏ não thái dương. Dựa vào vị trí sang thương, chúng tôi có những kỹ thuật phẫu thuật khác nhau: lấy sang thương, lây sang thương và vùng nhu mô xung quanh (dưới $2 \mathrm{~cm}$ ). Bản chất sang thương não và mức độ lấy sang thương cũng góp phần kiểm soát cơn động kinh sau phẫu thuật [1], [3], [6].

\section{KẾT QUẢ NGHIÊN CỨU}

Trong thời gian nghiên cứu có 56 bệnh nhân được phấu thuật. Trong đó có 36 nữ và 20 nam, tỷ lệ nữ/nam là $1,8 / 1$. Tuổi nhỏ nhất là 14 tuổi và lớn nhất là 67 tuổi, tuổi trung bình là 39,2 tuổi, hai nhóm tuổi tập trung nhiều nhất từ 3039 và 40-49, chiếm tỷ lệ $51,8 \%$. Đa số các trường hợp có cơn động kinh cục bộ phức tạp $(69,6 \%)$, sang thương vỏ não thái dương $(71,4 \%)$ và thái dương trong $(28,6 \%)$. Thời gian theo dõi trung bình 12 tháng (6-48 tháng), $87,5 \%$ bệnh nhân hết cơn động kinh sau phâu thuật. Thuốc chống động kinh giảm trong 100\% trường hợp so với trước phẫu thuật.

\section{Phân loại cơn động kinh}

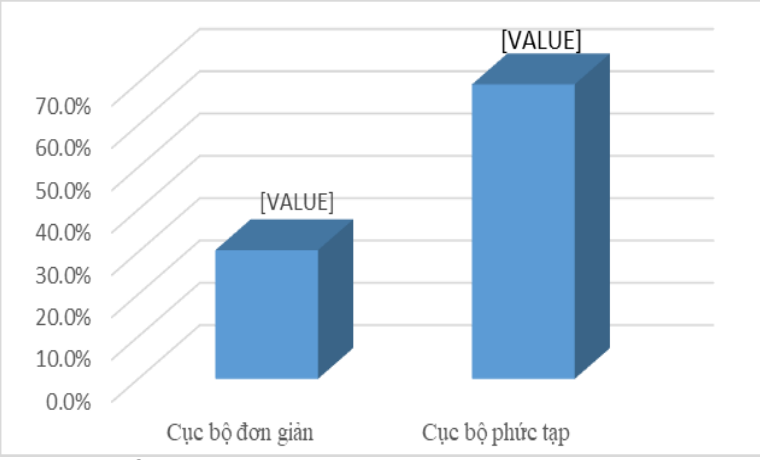

Biểu đồ 1: Phân loại cơn động kinh
Trong báo cáo này, cơn động kinh phổ biến nhất là cơn cục bộ phức tạp (39/56 bệnh nhân), chiếm tỷ lệ $69,6 \%$. Cơn động kinh có tiền triệu (22/56 bệnh nhân) chiếm 30,4\%.

Phân bố vị trí sang thương trong thùy thái dương

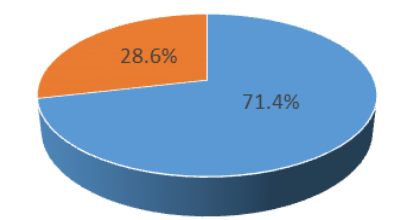

" Vỏ não thái dương - Thái dương trong

Biểu đồ 2: Phân bố vị trí sang thương trong thùy thái dương

Chúng tôi nhận thấy phần lớn bệnh nhân có phân bố sang thương ở vỏ não thái dương (40/56 bệnh nhân), chiếm tỷ lệ 71,4\%.

Kết quả phẫu thuật

Bảng 2. Kêt quả phẫu thuật theo Engel.

\begin{tabular}{|c|c|c|}
\hline Kết quả sau mổ & $\begin{array}{c}\text { Số bệnh } \\
\text { nhân }(\mathbf{n})\end{array}$ & $\begin{array}{c}\text { Tỉ lệ } \\
\text { \%o }\end{array}$ \\
\hline Hết cơn co giật & 49 & 87,5 \\
\hline Cải thiện cớn co giật & 4 & 7,1 \\
\hline Cải thiện ít & 3 & 5,4 \\
\hline Không cải thiện & 0 & 0 \\
\hline Tống cộng & $\mathbf{5 6}$ & $\mathbf{1 0 0 \%}$ \\
\hline
\end{tabular}

Chúng tôi ghi nhận đa số bệnh nhân hết cơn động kinh sau phẫu thuật (49/56 bệnh nhân), chiếm tỷ lệ 87,5\%.

Giải phẫu bệnh

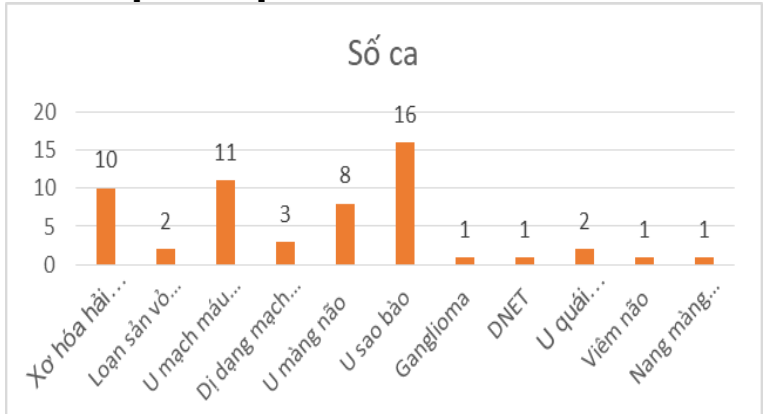

Biểu đồ 3. Kêt quả Giải phẫu bệnh.

Nhận xét: U sao bào, u mạch máu dạng hang và $u$ màng não là ba loại $u$ tần sinh thường gặp gây động kinh trong nghiên cứu. Kế đến là xơ hóa hải mã, và những thương tổn lành tính khác.

Trong nghiên cứu của chúng tôi chưa ghi nhận trường hợp nào tử vong sau phẫu thuật, có 2 trường hợp viêm màng não, 2 trường hợp liệt dây III khổng hoàn toàn và 3 trường hợp yểu nhẹ nửa người với sức cơ 4/5 sau phẫu thuật. 


\section{BÀN LUẬN}

Nghiên cứu này có 56 bệnh nhân, 36 nữ và 20 nam, tỉ lệ nữ/nam là 1,8/1 phù hợp với những báo cáo trong khu vực [1],[2]. Tuổi trung bình là 39,2 tuổi với độ lệch chuẩn là 14,2. Tuổi nhỏ nhất là 14 tuổi và lớn nhất là 67 tuổi, hai nhóm tuổi tập trung nhiêu nhất từ 30-39 và 40-49. Tuổi của bệnh nhân là một trong những yếu tố quãn trọng trong việc lựa chọn phương pháp phẫu thuật. Tuổi của bệnh nhân tại thời điểm phẫu thuật động kinh thùy thái dương càng cao sẽ làm tăng tai biến phẫu thuật. Bệnh nhân lớn tuổi thường có các bệnh lý nội khoa kèm theo, phẫu thuât lấy bán phân kèm hoăc xa phẫu hố trợ sau mổ hoặc xạ phẫu đơn thuân là phương pháp điều trị được lựa chọn [5].

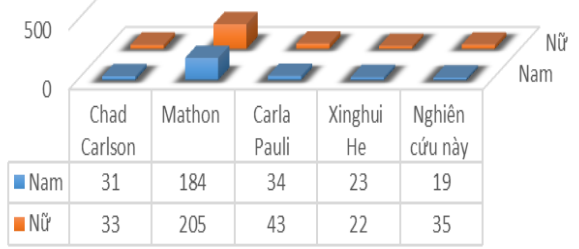

- Nam $\mathbf{\text { Nữ }}$

\section{Biểu đồ 4: Bảng so sánh tỉ lệ nam / nữ theo môt số tác giá.}

Phổ biến nhất là cơn động kinh cục bộ phức tạp hay cục bộ suy giảm ý thức, chuyển thành cơn co cứng co giật hai bên chiếm tỉ lệ $69,6 \%$. Động kinh cục bộ đớn giản hay động kinh cục bộ không ảnh hưởng ý thức, có tỉ lệ 30,4\%. Không có sự khác biệt nào về kiểu cớn được phát hiện giữa những bệnh nhân có tổn thương u não và những người không có tổn thương. Chúng tôi ghi nhận những cơn ngừng vận động hoặc kết hợp cơn động kinh cục bộ suy giảm ý thức và chuyển thành cơn co cứng co giật hai bên không có sự khác biệt theo từng loại sang thương não [6].

Tất cả bệnh nhân đều được chụp cộng hưởng từ sọ não và đo điện não đồ có sóng chậm và hoạt động dạng động kinh tại vùng tương ứng. Tất cả trường hợp có cơn động kinh cục bộ (100\%) với sang thương vỏ não thái dương $(71,4 \%)$ và thái dương trong (28,6\%). MRI não được coi là một kỹ thuật không xâm lấn chính xác để nhận biết các nguyên nhân về cấu trúc khác nhau gây ra các cơn động kinh khó kiểm soát. Một số nghiên cứu cho thây độ nhạy và độ đặc hiệu chẩn đoán cao của bệnh động kinh trên MRI. MRI độ phân giải cao là một phương pháp không xâm lấn đặc hiệu và có độ nhạy cao để chẩn đoán xơ hóa hải mã (HS). MRI định tính, định lượng thể tích vùng hải mã và tín hiệu $T 2$ (T2 relaxometry), rất nhạy và đặc hiệu trong việc phát hiện xơ hóa hải mã [6]. MRI não cũng có đô nhạy cao và đăc hiệu trong việc phát hiện các tổn thương khác ở thùy thái dương có thể có các biểu hiện lâm sàng tương tự như khối u, loạn sản, dị dạng mạch máu và các tổn thương khác, chẳng hạn như u não thùy thái dương. MRI não có thể phát hiện hâu hết các bệnh lý thường gặp gây ra chứng động kinh thân kinh: dị dạng phát triển vỏ não, tổn thương sau chấn thương và sau thiếu máu cục bộ, sẹo viêm nhiễm, u mạch máu dạng hang và dị dạng động tĩnh mạch não. Kết quả của chúng tôi phù hợp với nhiều nghiên cứu trên thế giới, đặc biệt với quốc gia đang phát triển có nguồn lực thấp, không có nhiều công cụ đánh giá trước phẫu thuật như đo điện não đồ xâm lấn, MEG, PET-CT...[1], [2], [3]. Qua nghiên cứu, chúng tôi ghi nhân sự phối hợp điên não và MRI góp phân nâng cao kết quả sau phẫu thuật động kinh thùy thái dương có sang thương.

Chúng tôi ghi nhận 49/56 bệnh nhân $(85,7 \%)$ hết cơn động kinh. Có 4 bệnh nhân ít cơn động kinh sau mổ, chiếm tỉ lệ 7,1\% và 3 bệnh nhân cải thiện cớn động kinh sau mổ, chiếm 5,4\%. Không ghi nhận trường hợp nào không cải thiện cơn sau phẫu thuật. Chúng tôi nhận thất đối với những thay đổi bệnh lý tương đương (u thân kinh đệm, u biểu mô thân kinh nghịch sản phôi, u mạch máu dạng hang, hoặc loạn sản vỏ não khu trú), tổn thương vùng thái dương và cắt bỏ thái dương trước có tỉ lệ tự do co giật tương tự [4].

Trong 56 trường hợp phẫu thuật, với thời gian theo dõi trung bình 12 tháng (6-48 tháng), 87,5\% bệnh nhân hết cơn động kinh sau phâu thuật. Thuốc chông động kinh giảm được trong 100\% trường hợp so với trước phẫu thuật. Kết quả sau phẫu thuật thành công cao, biến chứng phẫu thuật không đáng kể tương đồng với kết quả của những nghiên cứu khác trên thế giới [4], [6].

\section{KẾT LUẦN}

Chúng tôi đạt được tỉ lệ cao hết cơn động kinh sau phẫu thuật động kinh thùy thái dương có sang thương, thành công trong việc giảm thuốc chống động kinh. Chúng tôi tin tưởng rằng phẫu thuật là phương pháp điều trị hiệu quả cao, biến chứng thấp trong động kinh thùy thái dương có sang thương, mang lại chất lượng sống tốt cho người bệnh, gia đình và xã hội.

\section{KHUYẾN NGHI}

Động kinh thùy thái dương là loại động kinh thường gặp ở người trưởng thành, đa số kháng 
thuốc. Hậu quả động kinh khang thuốc ảnh hưởng đển chất lượng sống của bệnh nhân. Phẫu thuật động kinh thùy thái dương có sang thương là phẩu thuật an toàn và hiệu quả. Để mang lại sự điều trị tối ưu cho bệnh nhân, thây thuốc Thần Kinh nển giới thiệu sớm bệnh nhân đến những trung tâm phẫu thuật động kinh đánh giá và có phương pháp điều trị thích hợp nhất.

Các từ viết tắt: HS: Hippocampal Sclerosis

MRI: Magnetic Resonance Imaging

3T: 3 Tesla

\section{TÀI LIÊU THAM KHẢO}

1. Asadi-Pooya A. A., Ashjazadeh N., et al (2014), "Management of epilepsy in resourcelimited areas: Establishing an epilepsy surgery program in Iran", Med J Islam Repub Iran, 2014; $28(1): 24$.
2. Lim K. S., Ahmad S. A. B., Narayanan V., Rahmat K., et al (2017), "Level 4 comprehensive epilepsy program in Malaysia, a resource-limited country", Neurology Asia 2017; 22(4), pp. $299-305$.

3. Rocque B., Davis M., McClugage S. G., et al (2018), "Surgical treatment of epilepsy in Vietnam: program development and international collaboration", Neurosurg Focus 45 (4):E3, pp. 1-6.

4. Shih Y. H., Lirng J. F., Yen D. Y., Ho D. M. T. (2003). Surgery of intractable temporal lobe epilepsy presented with structural lesions. J Chin Med Assoc. 2003;66(10); pp. 565-571.

5. Sen $A_{.}$, Jette N., Husain M., Sander J. W. (2020), "Epilepsy in older people", The Lancet, Volume 395, ISSUE 10225, pp. 735-748

6. Wiebe S., Girvin J. P., Blume W. T., Elisasziw (2001), "A randomized, controlled trial of surgery for temporal-lobe epilepsy", The New England Journal of Medicine, Volume 345, Number 5, pp. 311-318.

\title{
ĐÁNH GIÁ TÁC DỤNG VÔ CẢM VÀ GIẢM ĐAU SAU MỔ CỦA GÂY TÊ TỦY SỐNG BẰNG BUPIVACAIN KẾT HỢP VỚI CÁC LIỀU MORPHIN KHÁC NHAU TRONG PHẪU THUÂTT CHẤN THƯO'NG CHI DƯớI
}

\author{
Dương Đức Phúc*, Công Quyết Thắng**, Lưu Quang Thùy***
}

\section{TÓM TẮT}

Mục tiêu: So sánh tác dụng vô cảm và giảm đau sau mổ của GTTS bằng $8 \mathrm{mg}$ bupivacain $0.5 \%$ kết hợp với $100 \mathrm{mcg}, 200 \mathrm{mcg}, 300 \mathrm{mcg}$ morphin trong phẫu thuật chấn thương chi dưới tại bệnh viện Quân Y 105 từ tháng 11/2018 đến tháng 04/2019. Phương pháp nghiên cứu: Thử nghiệm lâm sàng, tiến cứu, có nhóm so sánh. Bệnh nhần được chia vào 03 nhóm ngẫu nhiên: Nhóm I gồm 40 bệnh nhân được GTTS bằng bupivacain liều $8 \mathrm{mg}$ kểt hợp với morphin $0,10 \mathrm{mg}$. Nhóm II gồm 40 bệnh nhân được GTTS bằng bupivacain liều $8 \mathrm{mg}$ kết hợp với morphin $0,20 \mathrm{mg}$. Nhóm III gồm 40 bệnh nhân được GTTS bằng bupivacain liêu $8 \mathrm{mg}$ kết hợp với morphin $0,3 \mathrm{mg}$. Kết quả nghiên cứu: Thời gian vô cảm của 3 nhóm kéo dài và gần như nhau, với nhóm I, II và III là: ở mức $\mathrm{T}_{12}$ là $140 \div 235$ phút; ở mức $\mathrm{T}_{10}$ là $90 \div 190$ phút; ở mức $\mathrm{T}_{6}$ là $65 \div 135$ phút, sự khác biệt không có ý nghĩa thống kê với $p>0,05$. Nhóm III dưng liều $0,3 \mathrm{mg}$ morphin có thời gian giảm đau sau mổ dài nhất là: $29,87 \pm 7,00$ giờ, tiếp đó nhóm II dùng liều $0,2 \mathrm{mg}$ morphin là $22,33 \pm 4,44$ giờ và thấp nhất là nhóm I dùng liều $0,1 \mathrm{mg}$ morphin $18,28 \pm 3,86$ giờ, sự khác

*Bệnh viện Quân Y 105,

**Đai hoc Y Hà Nọi,

***Bênh viện Việt Đức

Chịu trách nhiệm chính: Dương Đức Phúc

Email: duongducphuc@gmail.com

Ngày nhận bài: 18.11.2020

Ngày phản biện khoa hoc: 5.01 .2021

Ngày duyệt bài: 20.01.2021 biệt có ý nghĩa thống kê với $p<0,05$. Kết luận: Liều dùng morphin giảm đau: nên dùng liều $0,3 \mathrm{mg}$ vì tác dụng thời gian giảm đau kéo dài so với liêu $0,2 \mathrm{mg}$ hay $0,1 \mathrm{mg}$.

Từ khóa: gây tê tủy sông, bupivacaine, morphin

\section{SUMMARY}

EVALUATE THE NERVE BLOCK EFFECTS AND POSTOPERATIVE PAIN MANAGEMENT OF SPINAL ANESTHESIA BY BUPIVACAIN COMBINED WITH DIFFERENT MORPHIN DOSES IN LOWER EXTREMITY SURGERY

Objective: To compare the nerve block effects and postoperative pain management of spinal anesthesia by $8 \mathrm{mg}$ bupivacaine $0.5 \%$ combined with $100 \mathrm{mcg}, 200 \mathrm{mcg}, 300 \mathrm{mcg}$ morphine in lower extremity surgery at 105 Military Hospital from November 2018 to April 2019. Method: prospective randomized controlled trial interventional study. The patients were divided into three random groups: Group I included 40 patients who received $8 \mathrm{mg}$ bupivacaine combined with $0,1 \mathrm{mg}$ morphine. Group II consisted of 40 patients who received $8 \mathrm{mg}$ bupivacaine combined with 0,2 mg morphine. Group III consisted of 40 patients who received $8 \mathrm{mg}$ bupivacaine combined with $0,3 \mathrm{mg}$ morphine. Results: The nerve block time of 3 groups lasted nearly the same, with group I, II and III were: at T12 level was $140 \div 235$ minutes; at T10 was $90 \div 190$ minutes; at T6 level was $65 \div 135$ minutes, there was no statistically significant with $p>0.05$. Group III with $0.3 \mathrm{mg}$ morphine had the longest postoperative analgesia time: $29.87 \pm 7.00$ hours, followed by group 